\title{
The Traffic Congestion Charging Fee Management Model Based on the System Dynamics Approach
}

\author{
Shuwei Jia, ${ }^{1}$ Kai Yang, ${ }^{1,2}$ Jinjin Zhao, ${ }^{3}$ and Guangle Yan $^{1}$ \\ ${ }^{1}$ School of Management, University of Shanghai for Science and Technology, Shanghai 200093, China \\ ${ }^{2}$ Complex Systems Science Research Center, University of Shanghai for Science and Technology, Shanghai 200093, China \\ ${ }^{3}$ University of Shanghai for Science and Technology, Shanghai 200093, China
}

Correspondence should be addressed to Shuwei Jia; shuweijia999666@163.com

Received 19 September 2016; Accepted 13 November 2016; Published 15 January 2017

Academic Editor: Nicolas Hudon

Copyright (C) 2017 Shuwei Jia et al. This is an open access article distributed under the Creative Commons Attribution License, which permits unrestricted use, distribution, and reproduction in any medium, provided the original work is properly cited.

\begin{abstract}
In recent years, the condition of urban traffic congestion in China has become more and more aggravated. Thus, from the social and environmental perspective, this paper has proposed a traffic congestion charging fee (TCCF) management model based on the system dynamics approach, taking Shanghai as a case study. The system dynamics approach applied in this paper focuses on the dynamic interrelations among some major variables in the TCCF management model. Hence, through a detailed discussion on these major variables, which are amount of car trips (ACT), growth of cars (GC), amount of $\mathrm{NO}_{x}$ generation (ANG), attraction degree of car trips (ADCT), per vehicle area of roads (PVAR), and degree of traffic congestion (DTC), it is discovered that, when TCCF equals 45 yuan/day * vehicle, the DTC has declined by $67.84 \%$ and the ANG by $33.09 \%$, which is a relatively satisfying solution to the traffic congestion problem.
\end{abstract}

\section{Introduction}

The urban traffic problem (e.g., congestion, exhaust emission, and safety) has become more and more serious. It now has gained word-wide concern. The traffic congestion not only brings bad effect on the traffic safety and causes traffic delays but also leads to severe air pollution. It exerts large adverse impact on human health $[1,2]$.

Traffic emission is the main source of air pollution in urban areas. $\mathrm{NO}_{x}$ is the major components in traffic emission as well as $\mathrm{PM}_{2.5}$ (PM with aerodynamic diameters of $2.5 \mu \mathrm{m}$ or less) that induces immune-system problems, respiratory and lung disease $[3,4]$. The urban traffic congestion frequently occurred in the densely populated regions such as Beijing, Shanghai, Guangzhou, and Wuhan. In particular, the continually increasing motor vehicles have become a significant contributor to the $\mathrm{NO}_{x}$ emission in these areas [5-7], and the rapid increase of motor vehicles emission in Shanghai has become a more and more important source for the formation of the severe haze [8]. The car ownership has increased rapidly in Shanghai and more than doubled between 2002 and 2007, reaching its peak in 2011 [9]. In addition, the regional transport had large impacts on the characterization of air pollution $\left(\mathrm{PM}_{2.5}\right)$ in Shanghai from 2011 to 2013 [10, 11]. In the source of $\mathrm{PM}_{2.5}$ in Huaniao Island ( $\sim 66 \mathrm{~km}$ to Shanghai), the contribution of motor vehicle is $\sim 27 \%$ [12]. Hence, the urban traffic congestion is becoming a hot topic and an urgent task in many areas such as Shanghai.

In the past few years, many researchers have established various traffic flow models and obtained some important results [13-16]. Armah et al. (2010) explored the traffic congestion and air pollution link in the city of Accra by the use of systems dynamics [17]. Zhang et al. (2012) studied the traffic congestion evaluation and signal control optimization based on wireless sensor networks and presented a model and algorithms for traffic flow data monitoring [18]. It is helpful to alleviate the urban traffic. Wang et al. (2014) studied the urban traffic congestion pricing model with the consideration of carbon emissions cost and put forward suitable proposals for the implementation of an urban traffic congestion pricing policy in China [19]. Ma and $\mathrm{He}$ (2016) researched the effects of the post-Olympics driving restrictions on air quality in 


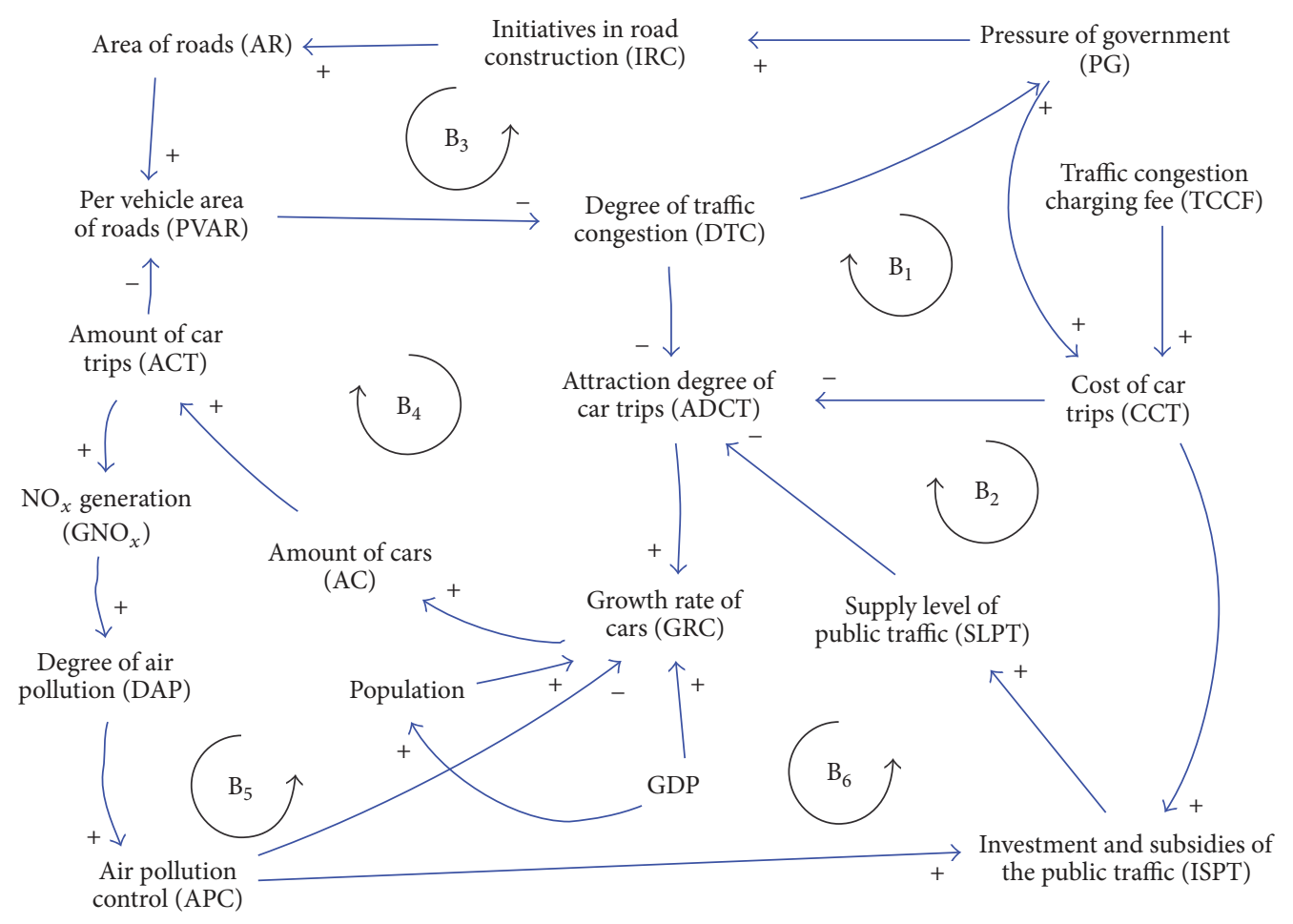

FIgURE 1: The causal-loop diagram of TCCF management model.

Beijing and had implemented a license plate-based traffic control measure, in order to reduce congestion and air pollution [20]. Mei et al. (2012) studied the combination of a guiding parking reliability model and parking choice behavior offering potential for parking guidance and information systems operators, in order to reduce the traffic congestion in central city areas [21]. Sabounchi et al. (2014) set up a dynamic simulation model based on congestion pricing scheme [22], while some scholars adopt the congestion pricing policy and study the traffic congestion problems [23-26].

However, there has been relatively little study on the urban traffic congestion management strategy in system dynamics. To this end, the TCCF management model has been put forward by using system dynamics. A relatively satisfactory solution was found through simulation and policy analysis. The simulation results not only alleviate traffic congestion but also help to reduce the haze pollution.

\section{Methods}

2.1. System Dynamics Methods. System dynamics (SD) is a modeling and simulation approach for better understanding the complex system and analyzing its dynamic behavior [27]. The structure of a system in SD is described by causal-loop diagrams [28]; hence, it provides a tool to test the effects of various strategies and polices in a system [29]. The results caused by change of schemes are automatically listed as graphs by the software Vensim ${ }^{\circledR}[30]$.

2.2. The Causal-Loop Diagram. Six causal-loop diagrams are delineated and analyzed in Figure 1. In this causal-loop diagram, the plus sign "+” means that the arrow-tail variable can increase the result to the arrow-head variable while the “_” symbol indicates an inverse relationship. The positive feedback loops would reinforce itself through its positive chain. On the contrary, the negative feedback loops would be relieved.

(i) Loop $B_{1}$. Degree of traffic congestion (DTC) $\stackrel{+}{\rightarrow}$ pressure of government $(\mathrm{PG}) \stackrel{+}{\rightarrow}$ cost of car trips $(\mathrm{CCT}) \stackrel{-}{\rightarrow}$ attraction degree of car trips $(\mathrm{ADCT}) \stackrel{+}{\rightarrow}$ growth rate of cars (GRC) $\stackrel{+}{\rightarrow}$ amount of cars $($ AC) $\stackrel{+}{\rightarrow}$ amount of car trips $(\mathrm{ACT}) \stackrel{-}{\rightarrow}$ per vehicle area of roads (PVAR) $\stackrel{-}{\rightarrow}$ degree of traffic congestion (DTC).

(ii) Loop $B_{2}$. Degree of traffic congestion (DTC) $\stackrel{+}{\rightarrow}$ pressure of government $(\mathrm{PG}) \stackrel{+}{\rightarrow}$ cost of car trips $(\mathrm{CCT}) \stackrel{+}{\rightarrow}$ investment and subsidies of the public traffic (ISPT) $\stackrel{+}{\rightarrow}$ supply level of public traffic (SLPT) $\stackrel{-}{\rightarrow}$ attraction degree of car trips $($ ADCT) $\stackrel{+}{\rightarrow}$ growth rate of cars $(\mathrm{GRC}) \stackrel{+}{\rightarrow}$ amount of cars $(\mathrm{AC}) \stackrel{+}{\rightarrow}$ amount of car trips $(\mathrm{ACT}) \stackrel{-}{\rightarrow}$ per vehicle area of roads $(\mathrm{PVAR}) \stackrel{-}{\rightarrow}$ degree of traffic congestion (DTC).

(iii) Loop $B_{3}$. Degree of traffic congestion (DTC) $\stackrel{+}{\rightarrow}$ pressure of government $(\mathrm{PG}) \stackrel{+}{\rightarrow}$ initiatives in road construction $(\mathrm{IRC}) \stackrel{+}{\rightarrow}$ area of roads $(\mathrm{AR}) \stackrel{+}{\rightarrow}$ per vehicle area of roads (PVAR) $\stackrel{-}{\rightarrow}$ degree of traffic congestion (DTC). 
(iv) Loop $B_{4}$. Per vehicle area of roads (PVAR) $\stackrel{-}{\rightarrow}$ degree of traffic congestion (DTC) $\stackrel{-}{\rightarrow}$ attraction degree of car trips $($ ADCT $) \stackrel{+}{\rightarrow}$ growth rate of cars $($ GRC) $\stackrel{+}{\rightarrow}$ amount of cars (AC) $\stackrel{+}{\rightarrow}$ amount of car trips (ACT) $\stackrel{-}{\rightarrow}$ per vehicle area of roads (PVAR).

(v) Loop $B_{5}$. $\mathrm{NO}_{x}$ generation $\left(\mathrm{GNO}_{x}\right) \stackrel{+}{\rightarrow}$ degree of air pollution $(\mathrm{DAP}) \stackrel{+}{\rightarrow}$ air pollution control $(\mathrm{APC}) \stackrel{-}{\rightarrow}$ growth rate of cars $(\mathrm{GRC}) \stackrel{+}{\rightarrow}$ amount of cars $(\mathrm{AC})$ $\stackrel{+}{\rightarrow}$ amount of car trips $(\mathrm{ACT}) \stackrel{+}{\rightarrow} \mathrm{NO}_{x}$ generation $\left(\mathrm{GNO}_{x}\right)$.

(vi) Loop $B_{6}$. Amount of car trips $(\mathrm{ACT}) \stackrel{+}{\rightarrow} \mathrm{NO}_{x}$ generation $\left(\mathrm{GNO}_{x}\right) \stackrel{+}{\rightarrow}$ degree of air pollution (DAP) $\stackrel{+}{\rightarrow}$ air pollution control $($ APC) $\stackrel{+}{\rightarrow}$ investment and subsidies of the public traffic (ISPT) $\stackrel{+}{\rightarrow}$ supply level of public traffic (SLPT) $\stackrel{-}{\rightarrow}$ attraction degree of car trips $(\mathrm{ADCT}) \stackrel{+}{\rightarrow}$ growth rate of cars $($ GRC) $\stackrel{+}{\rightarrow}$ amount of cars $(\mathrm{AC}) \stackrel{+}{\rightarrow}$ amount of car trips (ACT).

Loop $\mathrm{B}_{1}$ is a negative feedback loop, a change of any variable: for example, DTC would eventually affect itself in a negative way. An increase in the DTC will promote the increase of $\mathrm{PG}$, and larger pressure on the government indicates a severer traffic congestion condition, suggesting a higher TCCF; otherwise, it might be hard to ease the traffic congestion. So, larger PG leads to larger CCT, which finally results in less ADCT. Then decrease of GRC will reduce the AC, which will further reduce the ACT. Finally, less amount of ACT will result in a larger PVAR, which leads to a smaller DTC.

Loop $\mathrm{B}_{2}$ is also a negative feedback loop; the process of Loop $B_{2}$ is similar to the Loop $B_{1}$. Suppose there is an increase in the DTC, the PG and CCT would increase accordingly. This can gradually improve the ISPT. Subsequently, the better SLPT will lead to a decrease in ADCT, and the decrease of GRC will result in a smaller AC. Eventually, less ACT will promote the increase of PVAR and consequently reduce the DTC. Therefore, the variable DTC can affect itself negatively through the chain effects in this feedback loop.

In the same way, it is easy to analyze the loop $B_{3}-B_{6}$.

Loop $\mathrm{B}_{3}$ will largely depend on the road-building policy to solve the traffic congestion problem, but the effect of this policy is only temporary. It cannot fundamentally solve the problem and loop $\mathrm{B}_{4}$ can demonstrate this phenomenon. Namely, the original efforts committed to an increase of PVAR but the final amount will reduce.

Loops $\mathrm{B}_{5}$ and $\mathrm{B}_{6}$ adopt the air pollution control and investment and subsidies of the public traffic, respectively, in order to relieve the traffic congestion through the application of economic measure (such as TCCF) to reduce amount of car trips and $\mathrm{NO}_{x}$ generation. Hence, to some extent, it can inhibit the haze-fog.

Assumption 1. (1) The car which contains less than 7 seats is the major focus in this paper; (2) the $\mathrm{NO}_{2}$ of car emission is the main concern due to its harmfulness to human health; (3) the cost of TCCF will be invested in the traffic infrastructure construction and improvements of the public transport; (4) a proper range of TCCF is applied to the next 5 years.

2.3. The Stock-Flow Diagram. As noted above, the stock-flow diagram, as shown in Figure 2, is presented by using the Vensim software, and all descriptions of the major variables in the model are tabulated in detail in Table 1.

\section{Dynamic Simulation and Policy Analysis}

\subsection{In the Quantification of Major Variables}

Simulation Settings. Initial time $=2010$, final time $=2030$, time step $=0.5$, and unit of time is year.

(1) Official statistical data such as "Shanghai Statistical Year Book 2015” (method for quantification: $Q_{1}$ ) is as follows:

(a) From 2010 to 2014, the AAR in Shanghai are 2.567e+ $008 \mathrm{~m}^{2}, 2.6176 e+008 \mathrm{~m}^{2}, 2.6813 e+008 \mathrm{~m}^{2}, 2.729 e+$ $008 \mathrm{~m}^{2}$, and $2.7918 e+008 \mathrm{~m}^{2}$; therefore, the initial values of AAR and GRRC are $2.567 e+008 \mathrm{~m}^{2}$ and 0.0212 , respectively. In the same way, $A_{\text {initial value }}=$ $1.7572 e+006$ vehicles, $\mathrm{AP}_{\text {initial value }}=2.30266 e+007$ persons, $\mathrm{AGDP}_{\text {initial value }}=1.7166 e+012$ yuan.

(b) In 2010-2014 years, the BR in Shanghai are $7.13 \%$, 7.17\%o, 8.51\%o, 7.62\%o, and $8.64 \%$. So, $\mathrm{BR}_{\text {average value } \approx 7.82 \% 0} \approx 0.00782$. Similarly, $\mathrm{DR}_{\text {average value }} \approx 8.06 \%=0.00806$, $\mathrm{NRPM}_{\text {average value } \approx 6.6 \% \text { o }} \approx 0.0066$, and $\mathrm{GGDP}_{\text {average value }} \approx 0.0855$.

(2) Existing literature (quantification method: $Q_{2}$ ): according to Yang et al. (2014), we can obtain the following results [31].
(a) $\mathrm{PVANE}=0.02$ ton/day $*$ vehicle.
(b) $\mathrm{CRNC}=0.5$
(c) $\mathrm{DR}=0.2$
(d) $\mathrm{SR}=0.067$

(3) Estimated value (quantification method: $Q_{3}$ ) is
(a) $\left(\mathrm{NO}_{x}\right)_{\text {initial value }} \approx 0.02 \times 175.72 \times 10^{4}=35144$ tons,
(b) calculation of ADC.

Definition 2 (see [32]). Assume that the images of zero starting point of the two behavioral sequences

$$
\begin{aligned}
& X_{i}=\left(x_{i}(1), x_{i}(2), \ldots, x_{i}(n)\right), \\
& X_{j}=\left(x_{j}(1), x_{j}(2), \ldots, x_{j}(n)\right)
\end{aligned}
$$

are

$$
\begin{aligned}
& X_{i}^{0}=\left(x_{i}^{0}(1), x_{i}^{0}(2), \ldots, x_{i}^{0}(n)\right), \\
& X_{j}^{0}=\left(x_{j}^{0}(1), x_{j}^{0}(2), \ldots, x_{j}^{0}(n)\right) .
\end{aligned}
$$




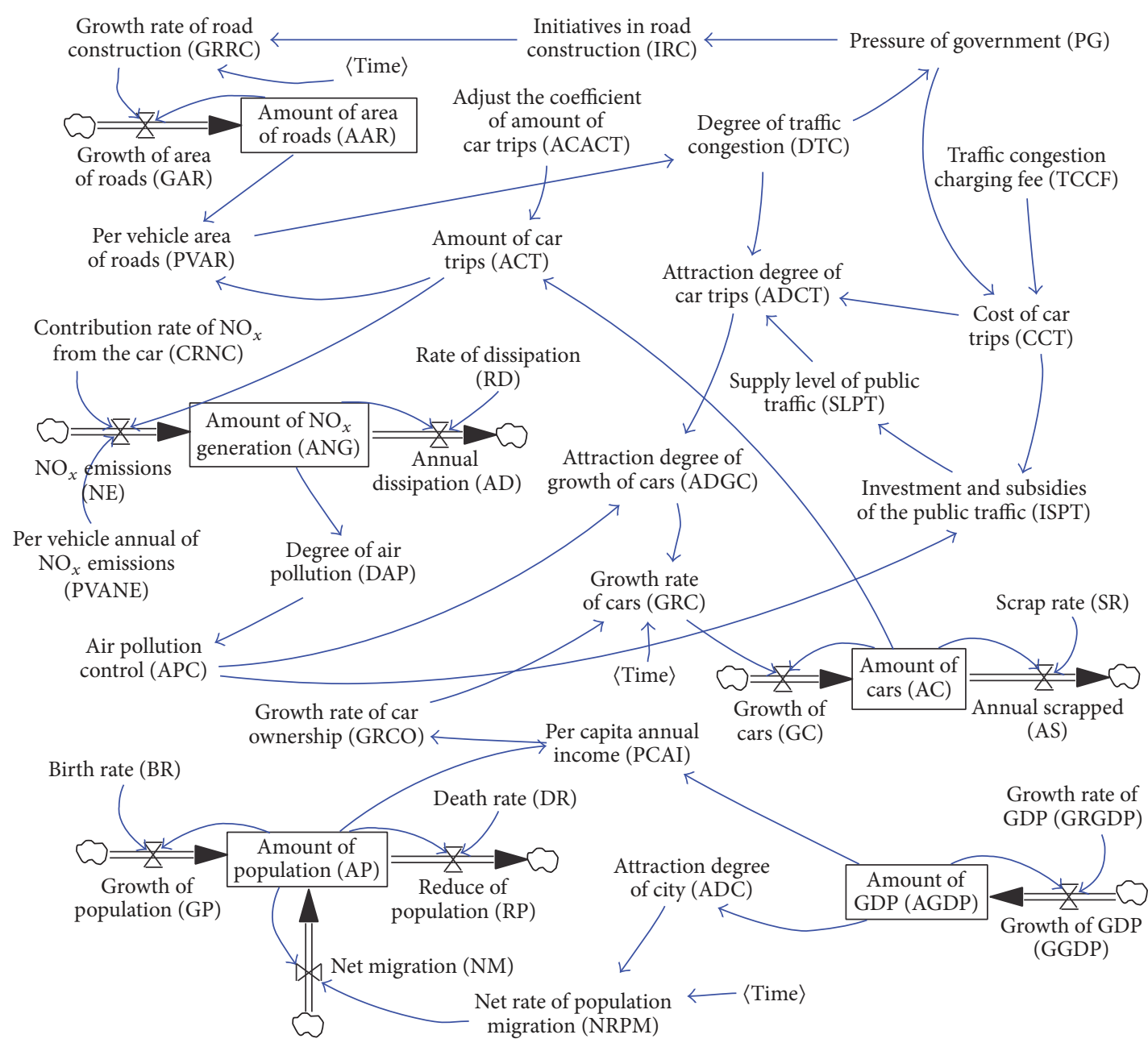

FIGURE 2: The stock-flow diagram of TCCF management model.

Assume that $X_{i}^{\prime}$ and $X_{j}^{\prime}$ are the initial images of $X_{i}$ and $X_{j}$, and the images of zero starting point of the two behavioral sequences $X_{i}^{\prime}, X_{j}^{\prime}$ are $X_{i}^{\prime 0}$ and $X_{j}^{\prime 0}$; then

$$
\begin{aligned}
& \xi_{i j}^{(1 / \sqrt{n}, 2)}=\left[1+\left|\sum_{k=2}^{n-1} x_{i}^{0}(k)+\frac{1}{2} x_{i}^{0}(n)\right|\right. \\
& \left.+\left|\sum_{k=2}^{n-1} x_{j}^{0}(k)+\frac{1}{2} x_{j}^{0}(n)\right|\right] \times[1 \\
& +\left|\sum_{k=2}^{n-1} x_{i}^{0}(k)+\frac{1}{2} x_{i}^{0}(n)\right|+\left|\sum_{k=2}^{n-1} x_{j}^{0}(k)+\frac{1}{2} x_{j}^{0}(n)\right| \\
& +\left|\sum_{k=2}^{n-1}\left[x_{i}^{0}(k)-x_{j}^{0}(k)\right]+\frac{1}{2}\left[x_{i}^{0}(n)-x_{j}^{0}(n)\right]\right|+\frac{1}{\sqrt{n}} \\
& \left.+\left(\sum_{k=1}^{n}\left|x_{i}^{0}(k)-x_{j}^{0}(k)\right|^{2}\right)^{1 / 2}\right]^{-1}
\end{aligned}
$$

$$
\begin{aligned}
& \gamma_{i j}^{(1 / \sqrt{n}, 2)}=\left[1+\left|\sum_{k=2}^{n-1} x_{i}^{\prime 0}(k)+\frac{1}{2} x_{i}^{\prime 0}(n)\right|\right. \\
& \left.+\left|\sum_{k=2}^{n-1} x_{j}^{\prime 0}(k)+\frac{1}{2} x_{j}^{\prime 0}(n)\right|\right] \times[1 \\
& +\left|\sum_{k=2}^{n-1} x_{i}^{\prime 0}(k)+\frac{1}{2} x_{i}^{\prime 0}(n)\right|+\left|\sum_{k=2}^{n-1} x_{j}^{\prime 0}(k)+\frac{1}{2} x_{j}^{\prime 0}(n)\right| \\
& +\left|\sum_{k=2}^{n-1}\left[x_{i}^{\prime 0}(k)-x_{j}^{\prime 0}(k)\right]+\frac{1}{2}\left[x_{i}^{\prime 0}(n)-x_{j}^{\prime 0}(n)\right]\right| \\
& \left.+\frac{1}{\sqrt{n}} \cdot\left(\sum_{k=1}^{n}\left|x_{i}^{\prime}(k)-x_{j}^{\prime}(k)\right|^{2}\right)^{1 / 2}\right]^{-1},
\end{aligned}
$$

are, respectively, called the quasi-"Euclidean" absolute degree of incidence (Q-EUGAID) and the quasi-"Euclidean" relative degree of incidence (Q-EUGRID); then

$$
\rho_{i j}^{(1 / \sqrt{n}, 2)}=\sigma_{1}^{(1 / \sqrt{n}, 2)} \xi_{i j}^{(1 / \sqrt{n}, 2)}+\sigma_{2}^{(1 / \sqrt{n}, 2)} \gamma_{i j}^{(1 / \sqrt{n}, 2)}
$$


TABLE 1: Descriptions on the variables quoted in this model.

\begin{tabular}{|c|c|c|c|c|}
\hline Abbreviations & Variable name & Unit & Variable type & Quantification method \\
\hline$\overline{\mathrm{AAR}}$ & Amount of area of roads & $\mathrm{m}^{2}$ & Stock & $Q_{1}$ \\
\hline $\mathrm{AC}$ & Amount of cars & Vehicle & Stock & $Q_{1}$ \\
\hline ACACT & Adjust the coefficient of amount of car trips & Dmnl & Parameter & $Q_{3}$ \\
\hline ACT & Amount of car trips & Vehicle & Auxiliary variable & \\
\hline $\mathrm{AD}$ & Annual dissipation & Ton/year & Flow & \\
\hline $\mathrm{ADC}$ & Attraction degree of city & $\%$ & Parameter & $Q_{3}$ \\
\hline ADCT & Attraction degree of car trips & $\%$ & Auxiliary variable & $Q_{3}$ \\
\hline ADGC & Attraction degree of growth of cars & $\%$ & Auxiliary variable & $Q_{3}$ \\
\hline ANG & Amount of $\mathrm{NO}_{x}$ generation & Ton & Stock & \\
\hline AGDP & Amount of GDP & Yuan & Stock & $Q_{1}$ \\
\hline AP & Amount of population & Person & Stock & $Q_{1}$ \\
\hline APC & Air pollution control & Dmnl & Auxiliary variable & $Q_{3}$ \\
\hline AS & Annual scrapped & Vehicle/year & Flow & \\
\hline $\mathrm{BR}$ & Birth rate & 1/year & Parameter & $Q_{1}$ \\
\hline CCT & Cost of car trips & Yuan/day $*$ vehicle & Auxiliary variable & $Q_{3}$ \\
\hline CRNC & Contribution rate of $\mathrm{NO}_{x}$ from the car & $\%$ & Parameter & $Q_{2}$ \\
\hline DAP & Degree of air pollution & Dmnl & Auxiliary variable & $Q_{3}$ \\
\hline $\mathrm{DR}$ & Death rate & 1/year & Parameter & $Q_{1}$ \\
\hline DTC & Degree of traffic congestion & Dmnl & Auxiliary variable & $Q_{3}$ \\
\hline GAR & Growth of area of roads & $\mathrm{m}^{2} /$ year & Flow & \\
\hline GC & Growth of cars & Vehicle/year & Flow & \\
\hline GGDP & Growth of GDP & Yuan/year & Flow & \\
\hline GP & Growth of population & Person/year & Flow & \\
\hline GRC & Growth rate of cars & 1/year & Auxiliary variable & $Q_{3}$ \\
\hline GRCO & Growth rate of car ownership & Dmnl & Auxiliary variable & $Q_{3}$ \\
\hline GRGDP & Growth rate of GDP & $1 /$ year & Parameter & $Q_{1}$ \\
\hline GRRC & Growth rate of road construction & $1 /$ year & Auxiliary variable & $Q_{1}$ \\
\hline IRC & Initiatives in road construction & Dmnl & Auxiliary variable & $Q_{3}$ \\
\hline ISPT & Investment and subsidies of the public traffic & Yuan/day $*$ vehicle & Auxiliary variable & $Q_{3}$ \\
\hline $\mathrm{NE}$ & $\mathrm{NO}_{x}$ emissions & Ton/year & Flow & \\
\hline NM & Net migration & Person/year & Flow & \\
\hline NRPM & Net rate of population migration & 1/year & Parameter & $Q_{1}$ \\
\hline PCAI & Per capita annual income & Yuan/person & Auxiliary & \\
\hline PG & Pressure of government & $\%$ & Auxiliary variable & $Q_{3}$ \\
\hline PVANE & Per vehicle annual of $\mathrm{NO}_{x}$ emissions & Ton/year $*$ vehicle & Parameter & $Q_{2}$ \\
\hline PVAR & Per vehicle area of roads & $\mathrm{m}^{2} /$ vehicle & Auxiliary variable & \\
\hline $\mathrm{RD}$ & Rate of dissipation & $1 /$ year & Parameter & $Q_{2}$ \\
\hline SLPT & Supply level of public traffic & Dmnl & Auxiliary variable & $Q_{3}$ \\
\hline $\mathrm{RP}$ & Reducing population & Person/year & Flow & \\
\hline SR & Scrap rate & $1 /$ year & Parameter & $Q_{2}$ \\
\hline TCCF & Traffic congestion charging fee & Yuan/day $*$ vehicle & Parameter & \\
\hline
\end{tabular}

is called the quasi-"Euclidean"synthetic degree of incidence (Q-EUGSID) of $X_{i}$ and $X_{j}$, where

$$
\begin{aligned}
\sigma_{1}^{(1 / \sqrt{n}, 2)} & >0, \\
\sigma_{2}^{(1 / \sqrt{n}, 2)} & >0, \\
\sigma_{1}^{(1 / \sqrt{n}, 2)}+\sigma_{2}^{(1 / \sqrt{n}, 2)} & =1 .
\end{aligned}
$$

This paper adopts the method of Q-EUGSID and assumes that the two behavioral sequences of $\mathrm{AGDP}_{\mathrm{China}(2010-2014)}$ and $\mathrm{AGDP}_{\text {Shanghai (2010-2014) }}$ are denoted as $X_{0}$ and $X_{1}$, where $X_{0}=$ $(408903.0,484123.5,534123.0,588018.8,636138.7)$ and $X_{1}=$ $(17165.98,19195.69,20181.72,21818.15,23567.70)$. Subsequently, calculating the values of Q-EUGAID and QEUGRID, we have that $\xi_{01}^{(1 / \sqrt{n}, 2)} \approx 0.4439, \gamma_{01}^{(1 / \sqrt{n}, 2)} \approx 0.8353$. Finally, let $\sigma_{1}^{(1 / \sqrt{n}, 2)}=0.5=\sigma_{2}^{(1 / \sqrt{n}, 2)}$; we can gain the value of 

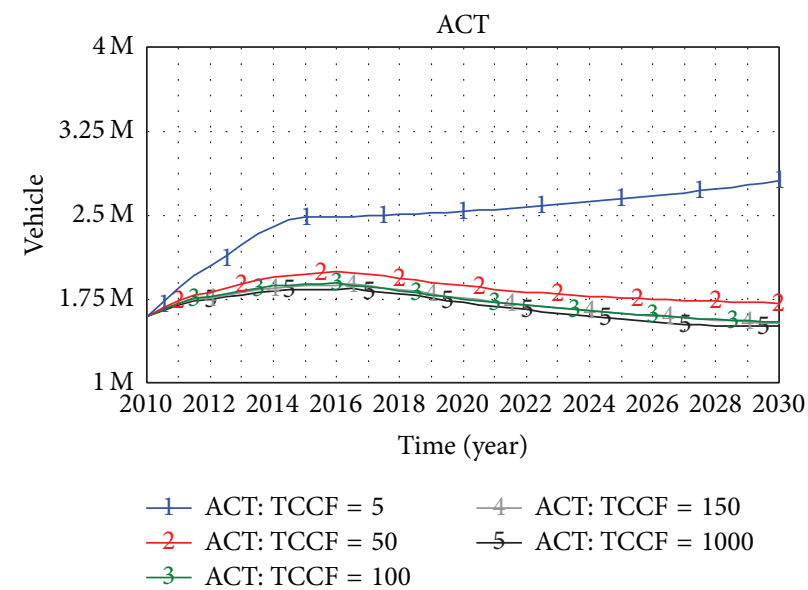

(a)

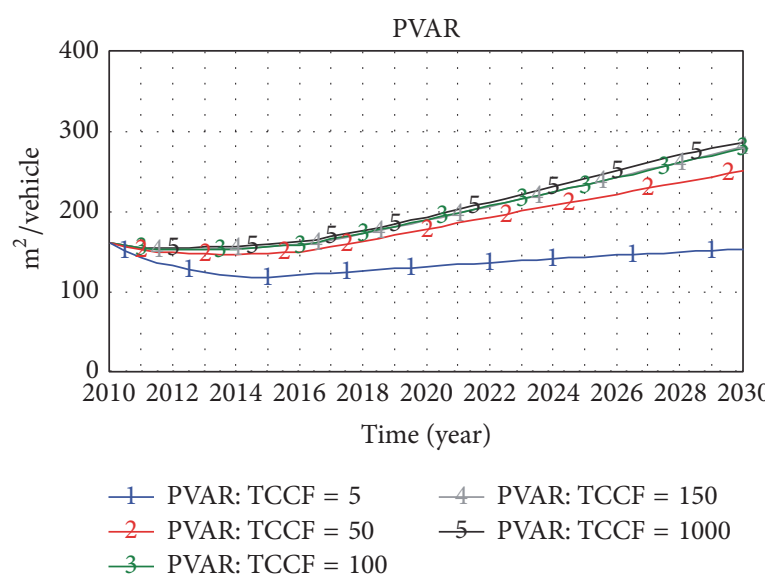

(c)

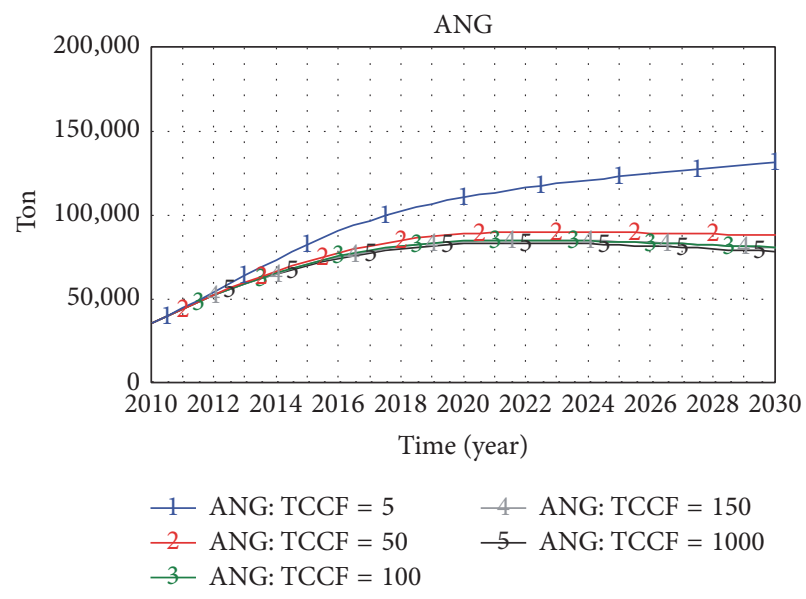

(b)
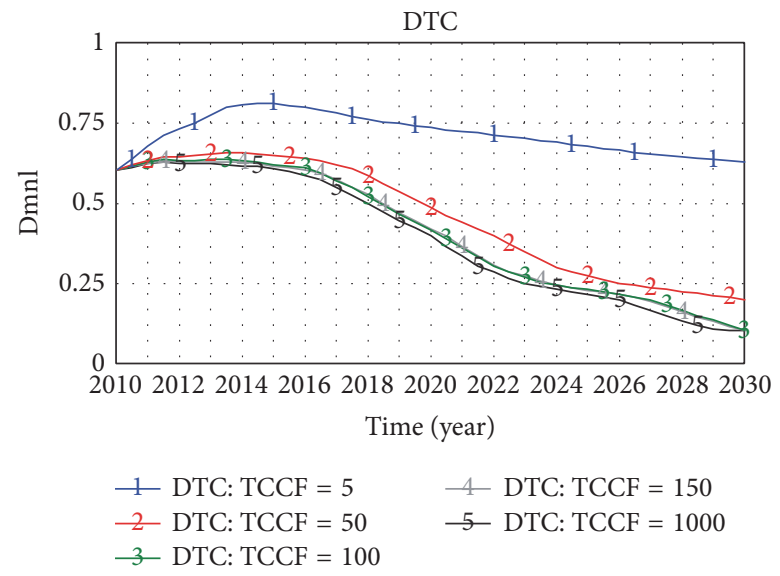

(d)

FIgure 3: Realistic test for the main variables. (a) ACT; (b) ANG; (c) PVAR; (d) DTC.

Q-EUGSID. Therefore, $\rho_{01}^{(1 / \sqrt{n}, 2)}=\sigma_{1}^{(1 / \sqrt{n}, 2)} \cdot \xi_{01}^{(1 / \sqrt{n}, 2)}+\sigma_{2}^{(1 / \sqrt{n}, 2)}$ $\cdot \gamma_{01}^{(1 / \sqrt{n}, 2)} \approx 0.6396$. Namely, $\mathrm{ADC} \approx 0.6396$.

Other variables can be described by the use of nonlinear function (such as graphical function and logic function), and the major variables and equations are explained in Appendix.

\subsection{Model Test and Simulation}

3.2.1. Realistic Test. It can be seen from Figure 3(a) that the ACT gets the minimum value when the TCCF $=1000$ yuan/day $*$ vehicle, while it reaches the maximum when the TCCF $=5$ yuan/day $*$ vehicle. This result is consistent with the reality. All of the curves are rising during the simulation period; however, with the increase of TCCF, ACT declines accordingly. Especially when the TCCF ranges between 5 and 50, ACT declines obviously; however, when the TCCF ranges between 50 and 100, ACT declines slightly. But when TCCF values are more than 100 yuan/day * vehicle, ACT stays almost unchanged. The varying pattern also applies to Figures 3(b), 3(c), and 3(d). Therefore, the TCCF should not go beyond 100 yuan/day * vehicle.
3.2.2. Sensitivity Analysis. From Figure 4(a), with years increasing, all curves rise first and descend later. For example, curve 5 is rising slowly till 2016; however, it decreases significantly slower during the year 2017 to 2030, even going like a horizontal line. The ACT decreases continuously along with the increase of the TCCF, and the gaps between each curve gradually shrink. Particularly, there is a biggest difference of ACT when TCCF ranges between 5 and 15, and a relatively big difference when TCCF $\in[15,45]$. Nevertheless, there is almost no change in ACT when the TCCF is higher than 45 yuan/day * vehicle. Hence, the TCCF is not always "bigger means better." It had better range between 15 and 45 yuan/day * vehicle.

As is shown in Figure 4(b), all curves continued to rise slowly. However, with the increasing of the TCCF, the gaps between these curves are narrowing. So, the increase of TCCF exerted a marginal decreasing effect on ANG (see curves 15). But there are almost no change in ANG when the TCCF is higher than 45 yuan/day * vehicle; this to a large extent demonstrated that the optimized TCCF should be close to 45 yuan/day $*$ vehicle. 

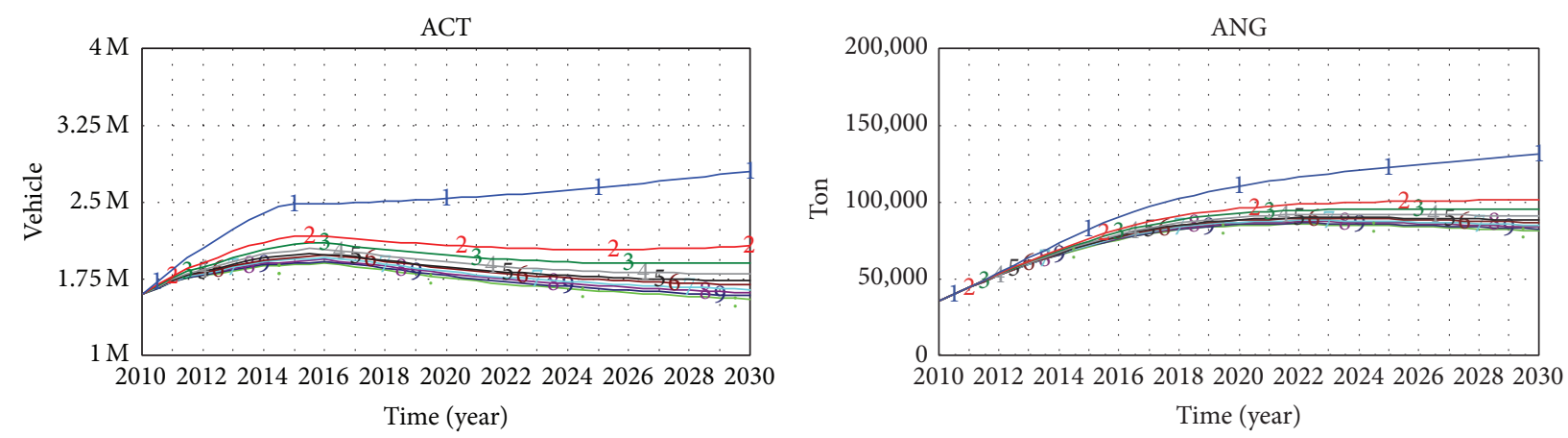

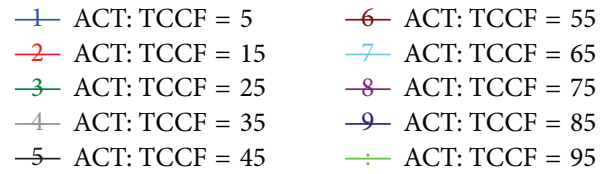

(a)

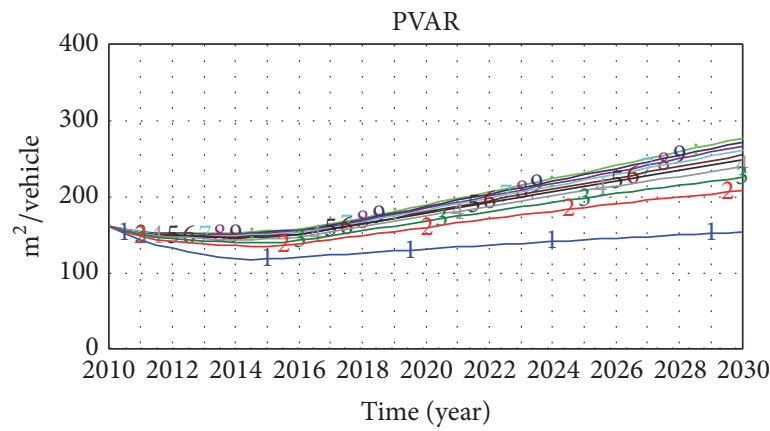

(c)

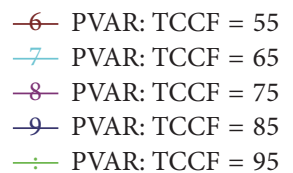

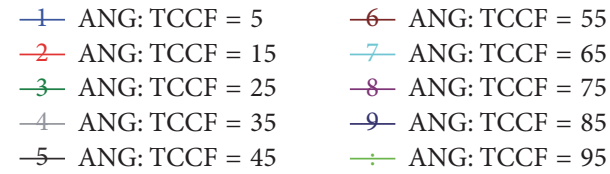

(b)

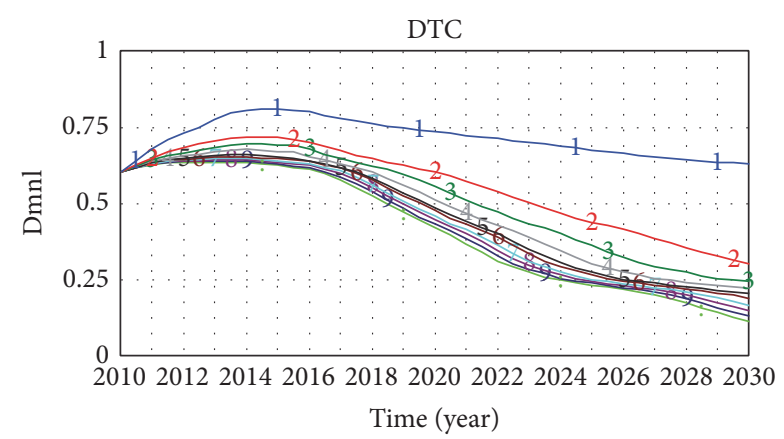

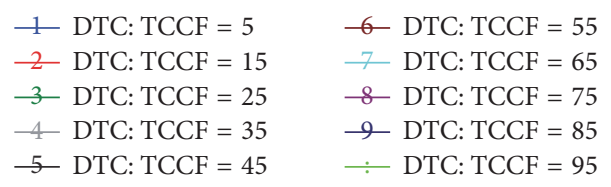

(d)

FIgURE 4: The effect of these major variables under different TCCF. (a) ACT; (b) ANG; (c) PVAR; (d) DTC.

On the contrary, Figure 4(c) indicated that all curves descend first and then gradually increase. Other properties are similar to Figure 4(a). Furthermore, the optimal TCCF (TCCF $\in[15,45])$ results in a significant decline in PVAR; however, the changes are very tiny when the TCCF is more than 45 yuan/day * vehicle.

From Figure 4(d), we can clearly see that all curves rise slowly first and then descend quickly. Take curve 5 as an example; it rises very slowly from 2010 to 2014; after 2014, it descends quickly. This is probably because of travelers' habit; the effect is not obvious in the early stage of the policy implementation. But in the latter period (2015-2030), the effect is more and more remarkable along with the continuous implementation and improvements of TCCF policy.

To sum up, the reasonable range of TCCT should be $[15,45]$, which reveals that the TCCF management model is valid and practical to a certain degree.

3.2.3. Sensitivity Test. A rational range between 15 and 45 was divided into sixteen equal portions, so each simulation step equals 2. Figures 5(a)-5(d) delineated that, although every curve has slight differences, the graphical shapes are almost consistent and did not appear too sensitive or insensitive.

3.3. Results Analysis. To further analyze, we can get Tables 2 and 3. As is shown in Table 2, the ACT has decreased steadily with the increase of the TCCF. In particular, it has decreased most significantly when TCCF $\in[5,15]$; it decreases relatively significantly when TCCF $\in[15,45]$. It is decreased slightly when TCCF is more than 45 yuan/day * vehicle. So, the TCCF should range between 15 and 45 yuan/day $*$ vehicle.

Similarly, the ANG and GC are all decreased to some degree, when TCCF $\in[15,45]$.

It is learned from Table 3 that the PVAR increases quickly with the increase of TCCF. But, the TCCF is not always the more, the better, because the PVAR rises most significantly when TCCF $\in[5,15]$, relatively significantly when TCCF $\epsilon$ $[15,45]$ and slightly when TCCF $\in[45,95]$. On the contrary, the increase of TCCF promotes the decrease of DTC. Table 3 

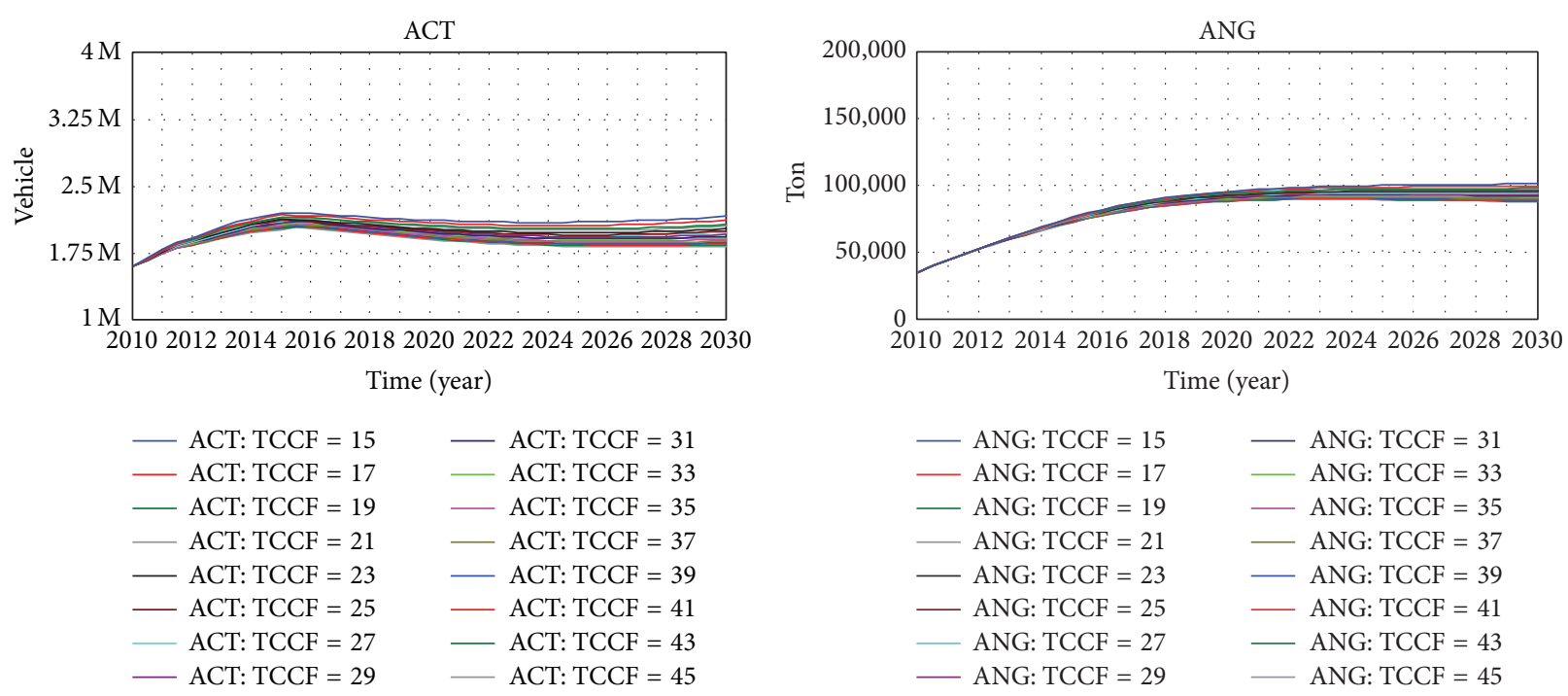

(a)
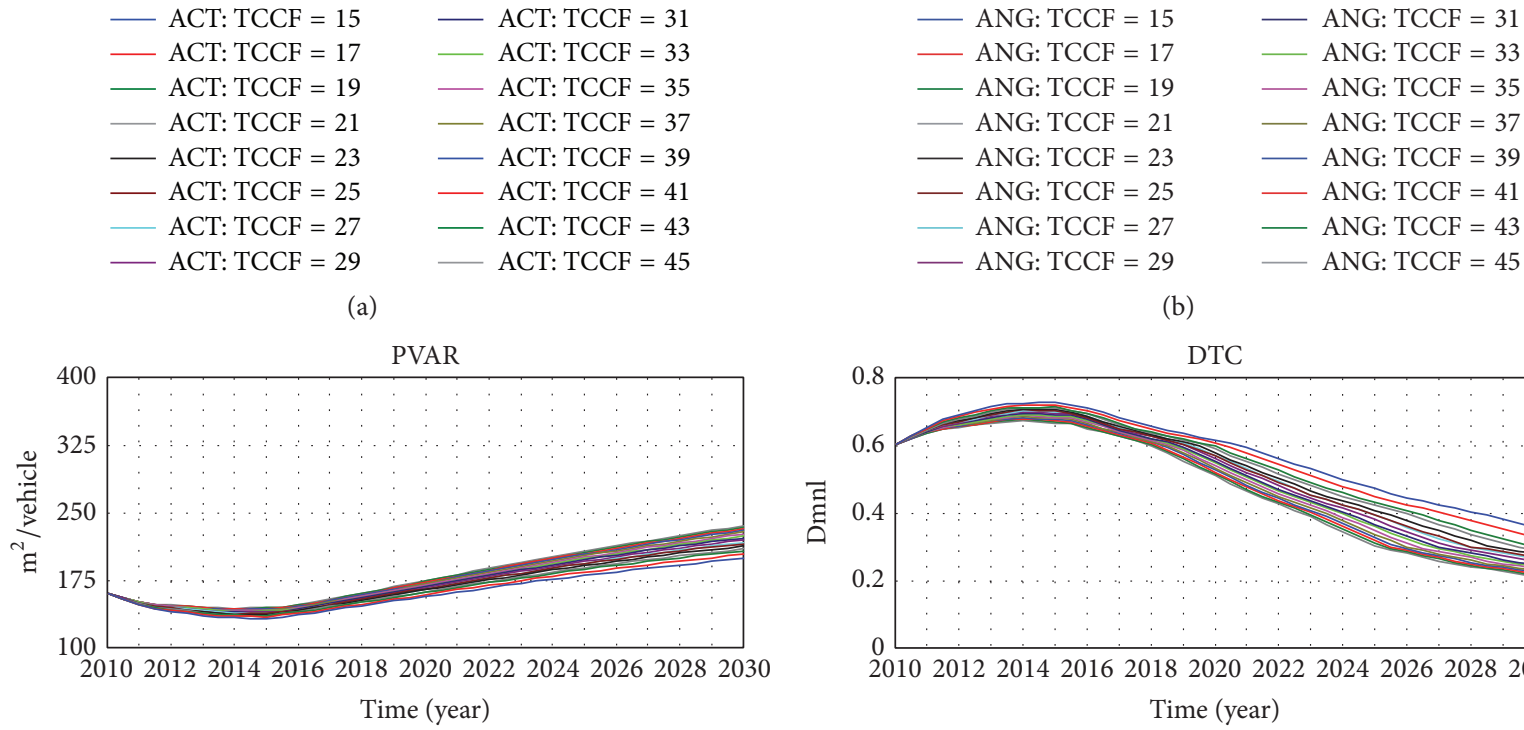

(b)

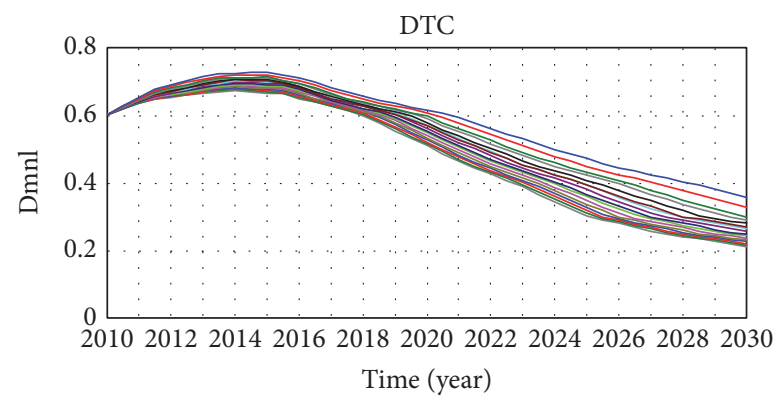

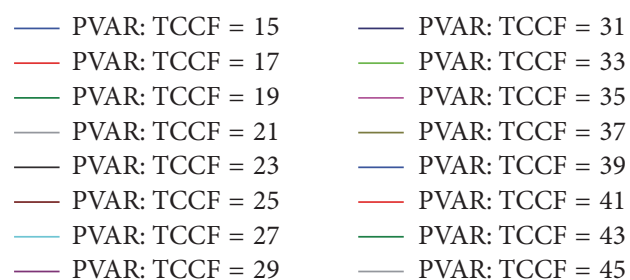

(c)

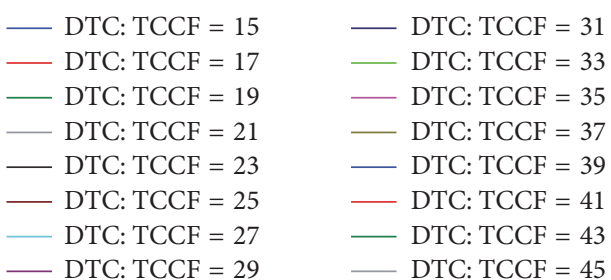

(d)

FIgure 5: Sensitivity test for the main variables. (a) ACT; (b) ANG; (c) PVAR; (d) DTC.

TABLE 2: The influence of ACT, GC, and ANG under different TCCF.

\begin{tabular}{lccccccccc}
\hline TCCF & ACT & Trend & Variation & GC & Trend & Variation & ANG & Trend & Variation \\
\hline 5 & $2.80203 e+006$ & - & - & 247932 & - & - & 131377 & - & - \\
$\mathbf{1 5}$ & $\mathbf{2 . 0 7 1 5 1 e}+\mathbf{0 0 6}$ & $\downarrow$ & $-\mathbf{2 6 . 0 7 \%}$ & $\mathbf{1 7 0 4 4 5}$ & $\downarrow$ & $\mathbf{- 3 1 . 2 5 \%}$ & $\mathbf{1 0 1 5 4 6}$ & $\downarrow$ & $-\mathbf{2 2 . 7 1 \%}$ \\
$\mathbf{2 5}$ & $\mathbf{1 . 9 0 7 2 6 e}+\mathbf{0 0 6}$ & $\downarrow$ & $-\mathbf{7 . 9 3 \%}$ & $\mathbf{1 4 6 9 0 2}$ & $\downarrow$ & $\mathbf{- 1 3 . 8 1 \%}$ & $\mathbf{9 5 0 4 4 . 1}$ & $\downarrow$ \\
$\mathbf{3 5}$ & $\mathbf{1 . 7 9 8 3 1 e}+\mathbf{0 0 6}$ & $\downarrow$ & $\mathbf{- 5 . 7 1 \%}$ & $\mathbf{1 3 1 5 7 5}$ & $\downarrow$ & $\mathbf{- 1 0 . 4 3 \%}$ & $\mathbf{9 0 7 4 4 . 4}$ & $\downarrow$ & $-\mathbf{6 . 4 0 \%}$ \\
$\mathbf{4 5}$ & $\mathbf{1 . 7 2 5 4 9 e + \mathbf { 0 0 6 }}$ & $\downarrow$ & $\mathbf{- 4 . 0 5 \%}$ & $\mathbf{1 2 1 6 5 7}$ & $\downarrow$ & $\mathbf{- 7 . 5 4 \%}$ & $\mathbf{8 7 9 0 8 . 8}$ & $\downarrow$ \\
55 & $1.6876 e+006$ & $\downarrow$ & $-2.20 \%$ & 116650 & $\downarrow$ & $-4.12 \%$ & 86584.4 & $\downarrow$ & $-\mathbf{3 . 1 2} \%$ \\
65 & $1.64308 e+006$ & $\downarrow$ & $-2.64 \%$ & 112187 & $\downarrow$ & $-3.83 \%$ & 84768 & $\downarrow$ & $-1.51 \%$ \\
75 & $1.61089 e+006$ & $\downarrow$ & $-1.96 \%$ & 108625 & $\downarrow$ & $-3.18 \%$ & 83487.6 & $\downarrow$ & $-1.51 \%$ \\
85 & $1.5791 e+006$ & $\downarrow$ & $-1.97 \%$ & 105548 & $\downarrow$ & $-2.83 \%$ & 82153.2 & $\downarrow$ & $-1.60 \%$ \\
95 & $1.55025 e+006$ & $\downarrow$ & $-1.83 \%$ & 102739 & $\downarrow$ & $-2.66 \%$ & 80941.9 & $\downarrow$ & $-1.47 \%$ \\
\hline
\end{tabular}


TABLE 3: The influence of PVAR, ADCT, and DCT under different TCCF.

\begin{tabular}{lccccccccc}
\hline TCCF & PVAR & Trend & Variation & ADCT & Trend & Variation & DTC & Trend & Variation \\
\hline 5 & 153.202 & - & - & 0.505177 & - & - & 0.628229 & - & - \\
$\mathbf{1 5}$ & $\mathbf{2 0 7 . 2 9 9}$ & $\uparrow$ & $\mathbf{3 5 . 3 1 \%}$ & $\mathbf{0 . 4 7 3 3 9 9}$ & $\downarrow$ & $\mathbf{- 6 . 2 9 \%}$ & $\mathbf{0 . 3 0 0 3 4 7}$ & $\downarrow$ & $-\mathbf{5 2 . 1 9 \%}$ \\
$\mathbf{2 5}$ & $\mathbf{2 2 5 . 0 7 5}$ & $\uparrow$ & $\mathbf{8 . 5 8 \%}$ & $\mathbf{0 . 4 4 4 6 8 6}$ & $\downarrow$ & $\mathbf{- 6 . 0 7 \%}$ & $\mathbf{0 . 2 4 2 4 0 4}$ & $\downarrow$ & $-\mathbf{1 9 . 2 9 \%}$ \\
$\mathbf{3 5}$ & $\mathbf{2 3 8 . 7 1}$ & $\uparrow$ & $\mathbf{6 . 0 6 \%}$ & $\mathbf{0 . 4 2 2 3 8 1}$ & $\downarrow$ & $\mathbf{- 5 . 0 2 \%}$ & $\mathbf{0 . 2 1 9 2 0 7}$ & $\downarrow$ & $\mathbf{- 9 . 5 7 \%}$ \\
$\mathbf{4 5}$ & $\mathbf{2 4 8 . 7 8 5}$ & $\uparrow$ & $\mathbf{4 . 2 2 \%}$ & $\mathbf{0 . 4 0 6 2 8 8}$ & $\downarrow$ & $\mathbf{- 3 . 8 1 \%}$ & $\mathbf{0 . 2 0 2 0 6 6}$ & $\downarrow$ & $-\mathbf{7 . 8 2} \%$ \\
55 & 254.37 & $\uparrow$ & $2.24 \%$ & 0.397655 & $\downarrow$ & $-2.12 \%$ & 0.185433 & $\downarrow$ & $-8.23 \%$ \\
65 & 261.264 & $\uparrow$ & $2.71 \%$ & 0.392307 & $\downarrow$ & $-1.34 \%$ & 0.162455 & $\downarrow$ & $-12.39 \%$ \\
75 & 266.484 & $\uparrow$ & $2.00 \%$ & 0.386856 & $\downarrow$ & $-1.39 \%$ & 0.145053 & $\downarrow$ & $-10.71 \%$ \\
85 & 271.849 & $\uparrow$ & $2.01 \%$ & 0.383006 & $\downarrow$ & $-1.00 \%$ & 0.12717 & $\downarrow$ & $-12.33 \%$ \\
95 & 276.907 & $\uparrow$ & $1.86 \%$ & 0.379269 & $\downarrow$ & $-0.98 \%$ & 0.110309 & $\downarrow$ & $-13.26 \%$ \\
\hline
\end{tabular}

TABLE 4: A reasonable value is compared with the base run simulation.

\begin{tabular}{lcccc}
\hline Variable & TCCF (yuan/day * vehicle) & \multirow{2}{*}{ Variation } & Trend \\
& 5 & 45 & & \\
\hline DTC & 0.628229 & 0.202066 & $-67.84 \%$ & $\downarrow$ \\
ANG (ton) & 131377 & 87908.8 & $-33.09 \%$ & $\downarrow$ \\
PVAR $\left(\mathrm{m}^{2}\right)$ & 153.202 & 248.785 & $62.39 \%$ & $\uparrow$ \\
ACT (vehicle) & $2.80203 e+006$ & $1.72549 e+006$ & $-38.42 \%$ & $\downarrow$ \\
ADCT & 0.505177 & 0.406288 & $-19.58 \%$ & $\downarrow$ \\
GC (vehicle) & 247932 & 121657 & $-50.93 \%$ & $\downarrow$ \\
\hline
\end{tabular}

also shows that ADCT decreases steadily with the increase of TCCF.

To some up, the relatively optimized TCCF not only reduces DTC evidently, but also effectively reduces the ANG. So, the reasonable TCCF should range between 15 and 45 yuan/day $*$ vehicle.

3.4. Policy Analysis and Optimization. Table 4 shows that, compared with base run simulation $(\mathrm{TCCF}=5$ yuan/day $*$ vehicle), when the TCCF $=45$ yuan/day $*$ vehicle, the DTC, ANG, ACT, ADCT, and GC will reduce by approximately $67.84 \%, 33.09 \%, 38.42 \%, 19.58 \%$, and $50.93 \%$, respectively, and the PVAR will increase about $62.39 \%$. These results reveal that it not only can vastly decrease the DTC, but also can availably control air pollution (especially the "haze-fog" pollution). Hence, the scope between 15 and 45 yuan/day * vehicle is a satisfied solution.

More specifically, it is quite obvious from Figure 6(a) that the two curves increase initially and decrease afterwards. But the change of curve 2 became more slowly from 2010 to 2014. After 2014, there was a sharp reduction of curve 2 and it dropped by $67.84 \%$ in 2030 (compare with curve 1). So, the effect is very obvious. Figure 6(b) shows that the increasing of curve 2 is very tardily and it is inching down like a line after 2020. Particularly, the ANG has dropped to about 87908.8 tons in 2030. Before and after comparative analysis, it has decreased by approximately $33.09 \%$ in 2030 . As shown in Figure 6(c), after 2014, curve 2 was significantly increased (about 62.39\% in 2030) compared with curve 1. Figure 6(d) illustrated that, by 2016, the rising of the ACT is very slow, and since 2016, it drops year by year. It has reduced about $38.42 \%$ in 2030 compared with before.

All of the above reflect essential research value.

3.5. The Trend of the Main Variables. As is shown in Figure 7, curve 3 (APC) rises sharply which looks like a jagged line; this phenomenon indicates that the government has strengthened the management of traffic congestion and air pollution. Along with the increase of the APC, we can get the following conclusions:

(i) ACT (curve 1): the ACT increases in the early stage of simulation period; however it decreases gradually since 2016, and it drops to around 1.7 million vehicles after 2025.

(ii) ANG (curve 2): the ANG has increased slowly between 2010 and 2022; however, it decreases year by year between 2023 and 2030 .

(iii) PVAR (curve 5): the PVAR increases significantly since 2015, so it has relieved the urban traffic congestion effectively.

(iv) DTC (curve 4): the significant decrease of DTC has demonstrated that the TCCF management model is flexible and practical to some extent.

\section{Discussion and Conclusion}

Different from the previous researches, in order to relieve the urban traffic congestion and the environmental problems caused by the high-speed urbanization, this paper explored the TCCF management model based on system dynamics approach. It has wide application prospect and significant research value. The major findings are summarized as follows.

(1) When the TCCF increases, the ACT, GC, ADCT, and DTC decrease accordingly; however, the PVAR increases with the increase of the TCCF. In particular, the DTC decreases around $67.84 \%$ in 2030 when the TCCF equals 45 yuan/day $*$ vehicle. Hence, it can effectively alleviate the traffic congestion in Shanghai.

(2) There is a steady decline of the ANG with the increase of the TCCF. Particularly, it has declined by nearly $29.87 \%$ in 2030 . This result indicates that it reduces 


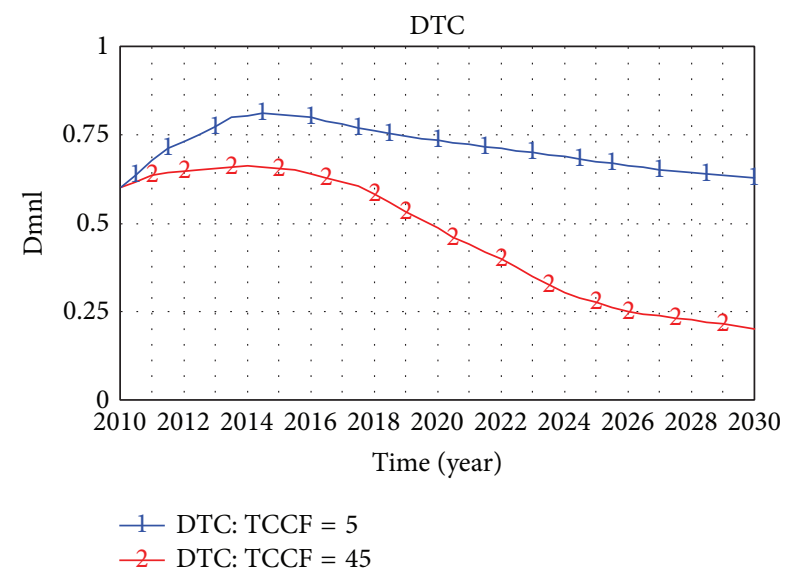

(a)

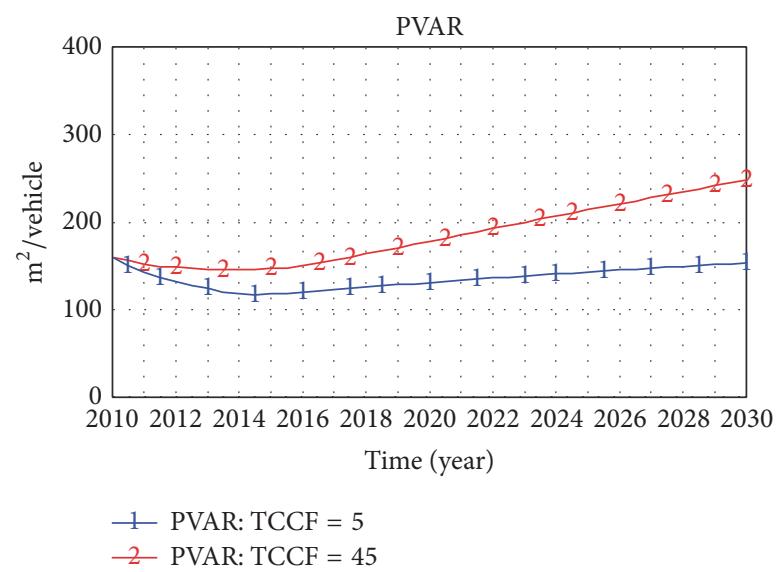

(c)

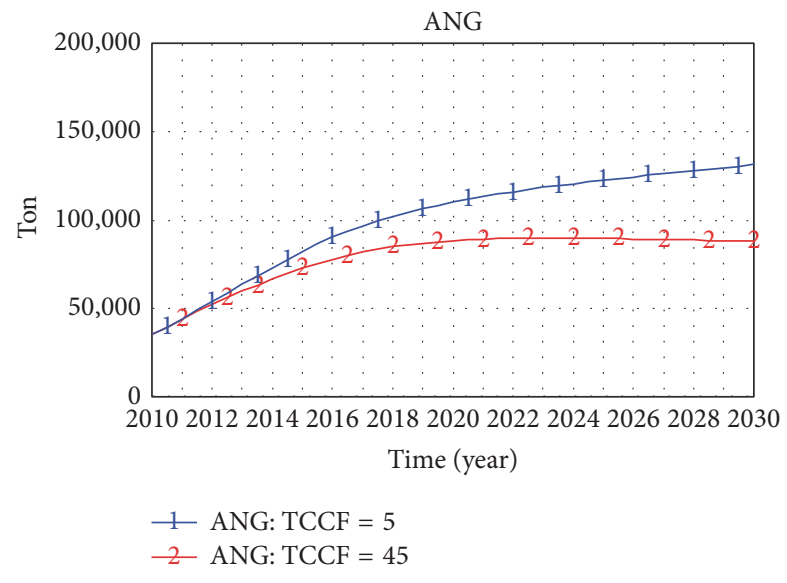

(b)

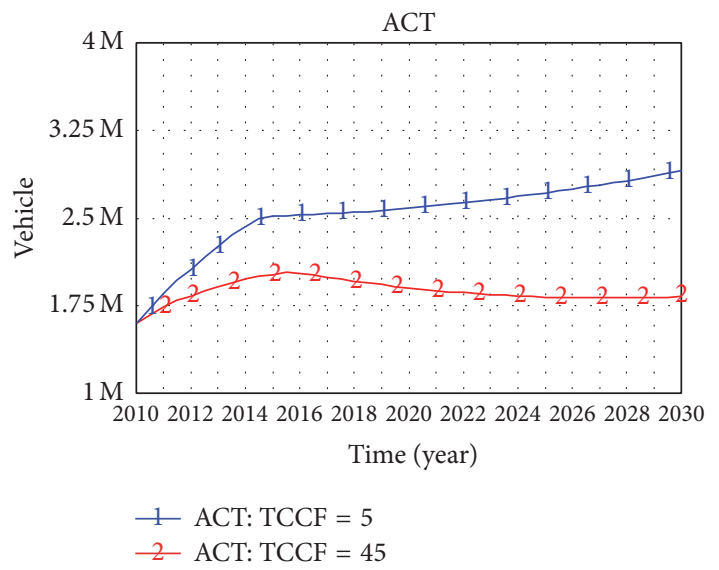

(d)

FIGURE 6: The influence of the major variables under different TCCF. (a) DTC; (b) ANG; (c) PVAR; (d) ACT.

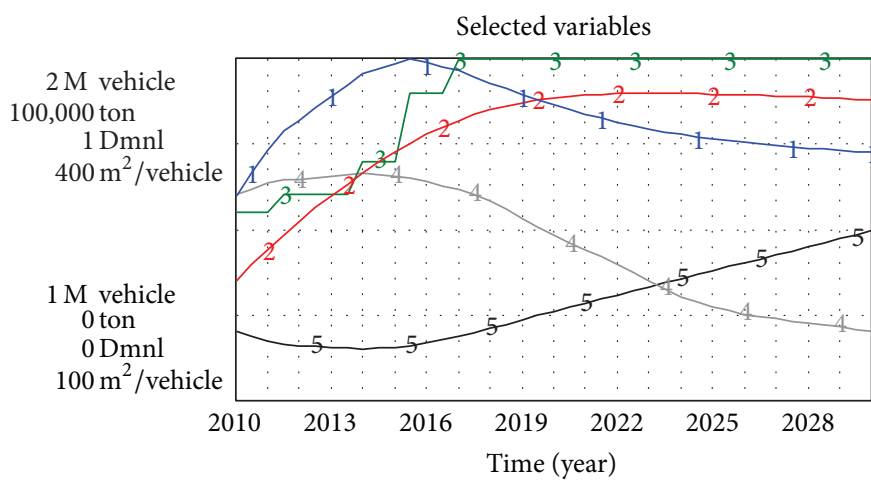

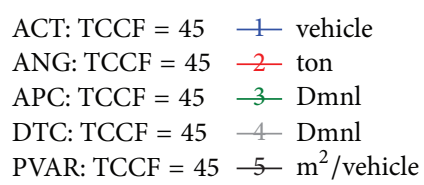

FIGURE 7: The trend of the main variables (when TCCF $=45$ yuan/day $*$ vehicle). 
car emission as well as the "haze-fog" pollution significantly.

(3) But it does not mean that the TCCF is the bigger, the better; it had better range between 15 and 45 .

Above all, when the TCCF rises, on the one hand, the PVAR has a dramatic increase (see Figures 4(c) and 6(c), Tables 3 and 4) and the DTC has a sharp decrease (see Figures 4(d) and 6(a), Tables 3 and 4); these results revealed that the TCCF management model is reliable and valid. On the other hand, the simulation and policy analysis has testified its practicability and rationality: the ANG has gradually declined (see Figures 4(b) and 6(b), Tables 2 and 4).

However, due to limited data, the model still has some limitations. (a) During the early stage of implementing the policy, the increase in the TCCF might weaken the public support, which may load more burdens on the government somehow. Therefore, sufficient publicity is necessary during the implementation to raise the public awareness that the traffic congestion charging fee policy aims at easing the urban traffic congestion and reducing environmental pollution. With a better understanding of the policy and its intention, the public support would be maintained through eliminating cognitive conflicts caused by the ignorance and stereotypes, relieving the burden on the government. (b) The range 15-45 yuan/day $*$ vehicle is not the perfect scheme; it is a relatively satisfying solution. When the living standards should be noticeably raised, the pricing range might be adjusted based on the actual conditions. (c) CCT and ISPT are increased with the increase of TCCF, so it will alleviate the traffic congestion to some degree, but the effects are still limited. From this perspective, we should take other policies into full account, including increasing the parking fee and the government subsidies on public transport, enhancing the trip of public transport, improving the quality of public transport services, and using alternative-energy cars (such as hydrogen fuel-cell buses and all-electric buses).

\section{Appendix}

\section{Summary of the Major Variables and Equations}

(1) AAR = INTEG $($ GAR, 2.5607e + 008).

(2) $\mathrm{AC}=$ INTEG $(\mathrm{GC}-\mathrm{AS}, 1.7572 e+006)$.

(3) ACACT $=1 / 2.5$.

(4) $\mathrm{ACT}=\mathrm{AC} *(1+\mathrm{ACACT}) * 0.65$.

(5) $\mathrm{AD}=\mathrm{ANG} * \mathrm{RD}$.

(6) $\mathrm{ADC}=0.6396$.

(7) $\mathrm{ADCT}=0.3 *(1-\mathrm{DTC})+0.45 / \mathrm{LN}(\mathrm{CCT})+(1-$ $\mathrm{SLPT}) * 0.25$.

(8) $\mathrm{ADGC}=(1-\mathrm{APC}) * 0.45+\mathrm{ADCT} * 0.55$.

(9) $\mathrm{ANG}=$ INTEG(NE $-\mathrm{AD}, 35144)$.

(10) AGDP $=$ INTEG(GGDP, $1.7166 e+012)$.

(11) $\mathrm{AP}=\operatorname{INTEG}(\mathrm{GP}+\mathrm{NM}-\mathrm{RP}, 2.30266 e+007)$.
(12) APC $=$ IF THEN ELSE $($ DAP $\geq 0.85,1$, IF THEN ELSE $(\mathrm{DAP} \geq 0.8,0.9$, IF THEN ELSE $(\mathrm{DAP} \geq 0.7,0.8, \mathrm{IF}$ THEN ELSE (DAP $\geq 0.6,0.7$, IF THEN ESE (DAP $\geq$ $0.5,0.6$, IF THEN ELSE (DAP $\geq 0.4,0.55$, IF THEN $\operatorname{ELSE}(\mathrm{DAP} \geq 0.3,0.4,0.3))))))$ ).

(13) $\mathrm{AS}=\mathrm{AC} * \mathrm{SR}$.

(14) $\mathrm{BR}=0.00782$.

(15) $\mathrm{CCT}=\mathrm{TCCF} *(1+\mathrm{PG})$.

(16) $\mathrm{CRNC}=0.5$.

(17) $\mathrm{DAP}=$ IF THEN ELSE $(A N G \geq 80000,0.9$, IF THEN ELSE $(A N G \geq 75000,0.8$, IF THEN ELSE $(A N G \geq$ 65000, 0.65, IF THEN ELSE (ANG $\geq 55000,0.55$, IF THEN ELSE (ANG $\geq 45000,0.5$, IF THEN ELSE $(\mathrm{ANG} \geq 35144,0.4$, IF THEN ELSE $(\mathrm{ANG} \geq 30000$, 0.35 , IF THEN ELSE (ANG $\geq 25000,0.3$, IF THEN ELSE $(A N G \geq 20000,0.25$, IF THEN ELSE (ANG $\geq$ $10000,0.2,0.1)))))))))$ ).

(18) $\mathrm{DR}=0.00806$.

(19) $\mathrm{DTC}=$ WITH LOOKUP $($ PVAR, $([(60,0)-(280,1)]$, $(90,0.9),(120.22,0.8),(127.56,0.75),(138.43,0.7)$, $(147.55,0.65), \quad(160.53,0.6), \quad(183.27,0.45)$, $(192.54,0.4),(207.28,0.3),(220.61,0.25),(250,0.2)$, $(280,0.1)))$.

(20) $\mathrm{GAR}=\mathrm{AAR} * \mathrm{GRRC}$.

(21) $\mathrm{GC}=\mathrm{AC} * \mathrm{GRC}$.

(22) GGDP $=$ AGDP $*$ GRGDP.

(23) $\mathrm{GP}=\mathrm{AP} * \mathrm{BR}$.

(24) $\mathrm{GRC}=0.6 * \mathrm{ADGC}^{2}+\mathrm{GRCO} * 0.4$.

(25) GRCO = WITH LOOKUP (PCAI, ([(65000, 0.06) $(100000,0.2)], \quad(66367,0.1038), \quad(69164,0.1149)$, (76074, 0.1929), (82560,0.1095), (83486.2,0.0918), (90993, 0.1045), (97370, 0.0855))).

(26) GRGDP $=0.0855$.

(27) $\mathrm{GRRC}=0.026$.

(28) $\operatorname{IRC}=$ WITH LOOKUP $(P G,([(0,0)-(1,1)]$, $(0,0),(0.1,0.11),(0.2,0.22),(0.3,0.34),(0.4,0.46)$, $(0.5,0.58), \quad(0.6,0.67), \quad(0.7,0.75), \quad(0.8,0.83)$, $(0.9,0.91)))$.

(29) $\mathrm{ISPT}=\mathrm{CCT} *(\mathrm{APC})^{0.5}$.

(30) $\mathrm{NE}=$ PVANE $*$ ACT $*$ CRNC.

(31) $\mathrm{NM}=\mathrm{AP} * \mathrm{NRPM}$.

(32) $\mathrm{NRPM}=0.0066$.

(33) $\mathrm{PCAI}=\mathrm{AGDP} / \mathrm{AP}$.

(34) $\mathrm{PG}=\operatorname{EXP}(\mathrm{DTC}-1)$.

(35) $\mathrm{PVANE}=0.02$.

(36) $\mathrm{PVAR}=\mathrm{AAR} / \mathrm{ACT}$.

(37) $\mathrm{RD}=0.2$.

(38) SLPT = WITH LOOKUP (ISPT, $([(0,0)-(180,1)]$, $(5,0.2),(10,0.3),(15,0.4),(20,0.5),(30,0.6),(40$, $0.65),(60,0.75),(80,0.8),(100,0.85),(150,0.95)))$. 
(39) $\mathrm{RP}=\mathrm{AP} * \mathrm{DR}$.

(40) $\mathrm{SR}=0.067$.

(41) $\mathrm{TCCF}=x$.

\section{Competing Interests}

The authors declare that they have no competing interests.

\section{Acknowledgments}

This work has been partially supported by the Hujiang Foundation of China (A14006) and Shanghai First-Class Academic Discipline Project (S1201YLXK).

\section{References}

[1] Z. Zhang, J. Wang, L. Chen et al., "Impact of haze and air pollution-related hazards on hospital admissions in Guangzhou, China," Environmental Science and Pollution Research, vol. 21, no. 6, pp. 4236-4244, 2014.

[2] Q. Zhang, K. He, and H. Huo, "Policy: Cleaning China's air," Nature, vol. 484, no. 7393, pp. 161-162, 2012.

[3] M. R. Heal, P. Kumar, and R. M. Harrison, "Particles, air quality, policy and health," Chemical Society Reviews, vol. 41, no. 19, pp. 6606-6630, 2012.

[4] S. J. Jin, J. K. Guo, S. Wheeler, L. Y. Kan, and S. Q. Che, "Evaluation of impacts of trees on PM2.5 dispersion in urban streets," Atmospheric Environment, vol. 99, no. 99, pp. 277-287, 2014.

[5] J. Lang, S. Cheng, W. Wei, Y. Zhou, X. Wei, and D. Chen, "A study on the trends of vehicular emissions in the BeijingTianjin-Hebei (BTH) region, China," Atmospheric Environment, vol. 62, pp. 605-614, 2012.

[6] J. Wang, Z. Hu, Y. Chen, Z. Chen, and S. Xu, "Contamination characteristics and possible sources of PM10 and PM2.5 in different functional areas of Shanghai, China," Atmospheric Environment, vol. 68, pp. 221-229, 2013.

[7] F. Zhang, Z. W. Wang, H. R. Cheng, X. P. Lv, and W. Gong, "Seasonal variations and chemical characteristics of $\mathrm{PM}_{2.5}$ in Wuhan, Central China," Science of The Total Environment, vol. 518-519, pp. 97-105, 2015.

[8] Q. Z. Wang, G. S. Zhuang, K. Huang et al., "Probing the severe haze pollution in three typical regions of China: characteristics, sources and regional impacts," Atmospheric Environment, vol. 120, pp. 76-88, 2015.

[9] M. Francesch-Huidobro, "Climate change and energy policies in Shanghai: a multilevel governance perspective," Applied Energy, vol. 164, pp. 45-56, 2016.

[10] H. L. Wang, L. P. Qiao, S. R. Lou et al., "PM2.5 pollution episode and its contributors from 2011 to 2013 in urban Shanghai, China," Atmospheric Environment, vol. 123, pp. 298-305, 2015.

[11] H. L. Wang, L. P. Qiao, S. R. Lou et al., "Chemical composition of $\mathrm{PM}_{2.5}$ and meteorological impact among three years in urban Shanghai, China," Journal of Cleaner Production, vol. 112, pp. 1302-1311, 2016.

[12] F. W. Wang, T. Lin, Y. Y. Li, T. Y. Ji, C. L. Ma, and Z. G. Guo, "Sources of polycyclic aromatic hydrocarbons in PM2.5 over the East China Sea, a downwind domain of East Asian continental outflow," Atmospheric Environment, vol. 92, no. 9, pp. 484-492, 2014.
[13] T.-Q. Tang, W.-F. Shi, H.-Y. Shang, and Y.-P. Wang, "An extended car-following model with consideration of the reliability of inter-vehicle communication," Measurement, vol. 58, no. 11, pp. 286-293, 2014.

[14] T. Q. Tang, J. G. Li, H. J. Huang, and X. B. Yang, "Acarfollowingmodelwithreal-timeroadconditionsandnumerical tests," Measurement, vol. 48, no. 1, pp. 63-76, 2014.

[15] T. Tang, W. Shi, H. Shang, and Y. Wang, "A new car-following model with consideration of inter-vehicle communication," Nonlinear Dynamics, vol. 76, no. 4, pp. 2017-2023, 2014.

[16] T.-Q. Tang, J. He, S.-C. Yang, and H.-Y. Shang, "A car-following model accounting for the driver's attribution," Physica A, vol. 413, pp. 583-591, 2014.

[17] F. A. Armah, D. O. Yawson, and A. A. N. M. Pappoe, "A systems dynamics approach to explore traffic congestion and air pollution link in the city of Accra, Ghana," Sustainability, vol. 2, no. 1, pp. 252-265, 2010.

[18] W. Zhang, G. Z. Tan, N. Ding, and G. Y. Wang, "Traffic congestion evaluation and signal control optimization based on wireless sensor networks: model and algorithms," Mathematical Problems in Engineering, vol. 2012, Article ID 573171, 17 pages, 2012.

[19] J. Wang, L. Chi, X. Hu, and H. Zhou, "Urban traffic congestion pricing model with the consideration of carbon emissions cost," Sustainability, vol. 6, no. 2, pp. 676-691, 2014.

[20] H. Ma and G. Z. He, "Effects of the post-olympics driving restrictions on air quality in Beijing," Sustainability, vol. 8, no. 9, p. 902, 2016.

[21] Z. Y. Mei, Y. Tian, and D. P. Li, "Analysis of parking reliability guidance of urban parking variable message sign system," Mathematical Problems in Engineering, vol. 53, pp. 244-247, 2012.

[22] N. S. Sabounchi, K. P. Triantis, S. Sarangi, and S. Liu, "Dynamic simulation modeling and policy analysis of an area-based congestion pricing scheme for a transportation socioeconomic system," Transportation Research Part A: Policy and Practice, vol. 59, pp. 357-383, 2014.

[23] J. Eliasson, L. Hultkrantz, L. Nerhagen, and L. S. Rosqvist, "The Stockholm congestion-charging trial 2006: overview of effects," Transportation Research Part A: Policy and Practice, vol. 43, no. 3, pp. 240-250, 2009.

[24] J. Eliasson, "A cost-benefit analysis of the Stockholm congestion charging system," Transportation Research Part A: Policy and Practice, vol. 43, no. 4, pp. 468-480, 2009.

[25] J. Eliasson, "The role of attitude structures, direct experience and reframing for the success of congestion pricing," Transportation Research Part A: Policy and Practice, vol. 67, pp. 81-95, 2014.

[26] N. Kaida and K. Kaida, "Spillover effect of congestion charging on pro-environmental behavior," Environment, Development and Sustainability, vol. 17, no. 3, pp. 409-421, 2015.

[27] J. W. Forester, Industrial Dynamics, MIT Press, 1961.

[28] D. Das and P. Dutta, "A system dynamics framework for integrated reverse supply chain with three way recovery and product exchange policy," Computers \& Industrial Engineering, vol. 66, no. 4, pp. 720-733, 2013.

[29] S. Wei, H. Yang, J. Song, K. C. Abbaspour, and Z. Xu, "System dynamics simulation model for assessing socio-economic impacts of different levels of environmental flow allocation in the Weihe River Basin, China," European Journal of Operational Research, vol. 221, no. 1, pp. 248-262, 2012. 
[30] W. Zhao, H. Ren, and V. S. Rotter, "A system dynamics model for evaluating the alternative of type in construction and demolition waste recycling center-the case of Chongqing, China," Resources, Conservation and Recycling, vol. 55, no. 11, pp. 933-944, 2011.

[31] H.-X. Yang, J.-D. Li, H. Zhang, and S.-Q. Liu, "Research on the governance of urban traffic jam based on system dynamics," Xitong Gongcheng Lilun yu Shijian/System Engineering Theory and Practice, vol. 34, no. 8, pp. 2135-2143, 2014.

[32] S. W. Jia and G. L. Yan, "Optimization algorithm of Q-EUGSID and its application," Application Research of Computers, vol. 33, no. 11, pp. 3353-3357, 2016 (Chinese). 


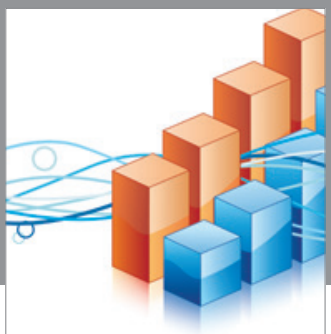

Advances in

Operations Research

vatem alat4

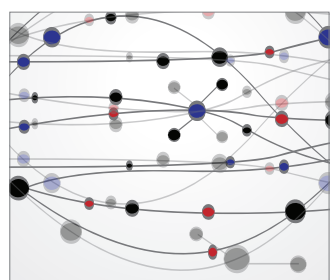

\section{The Scientific} World Journal
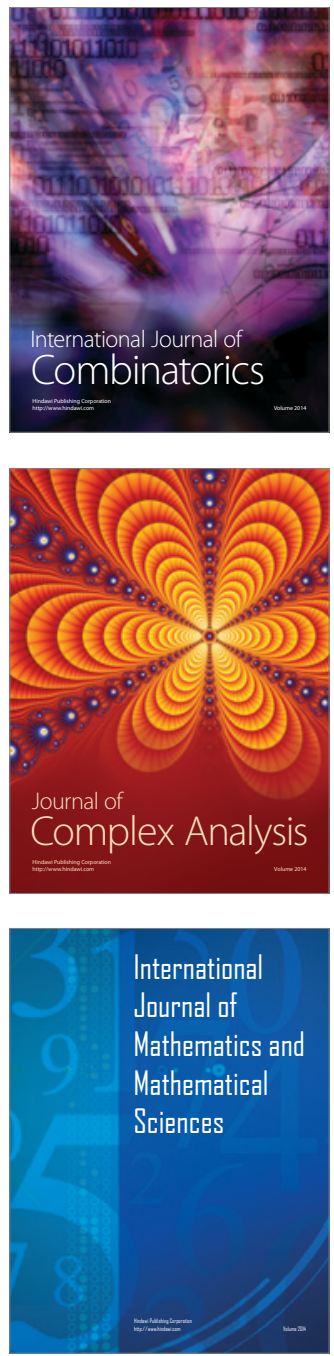
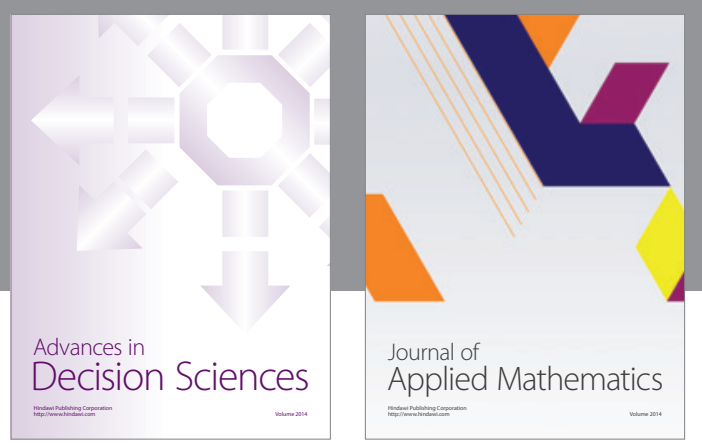

Algebra

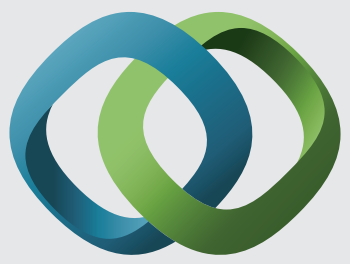

\section{Hindawi}

Submit your manuscripts at

https://www.hindawi.com
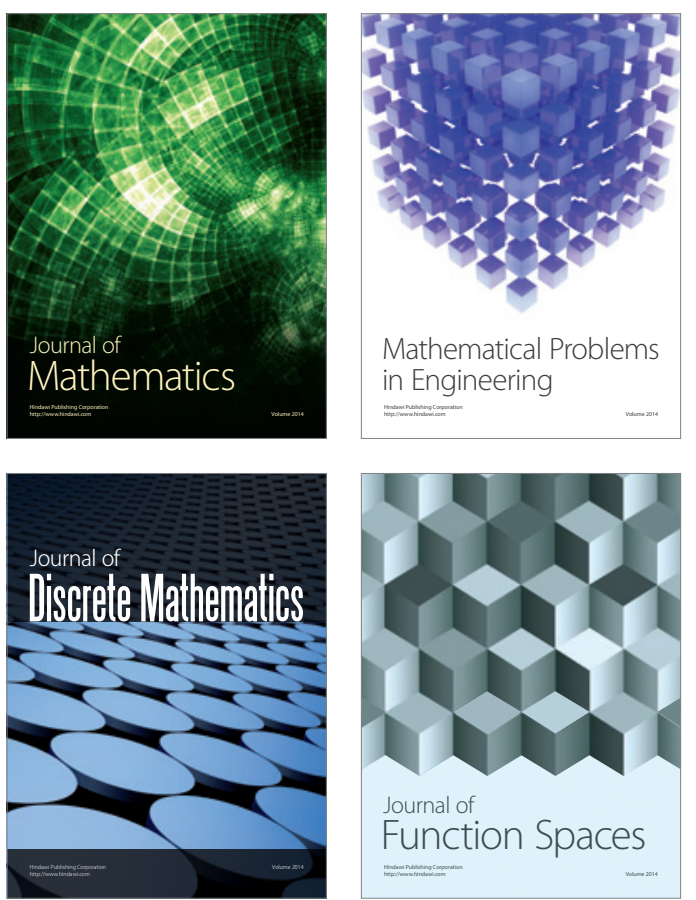

Mathematical Problems in Engineering
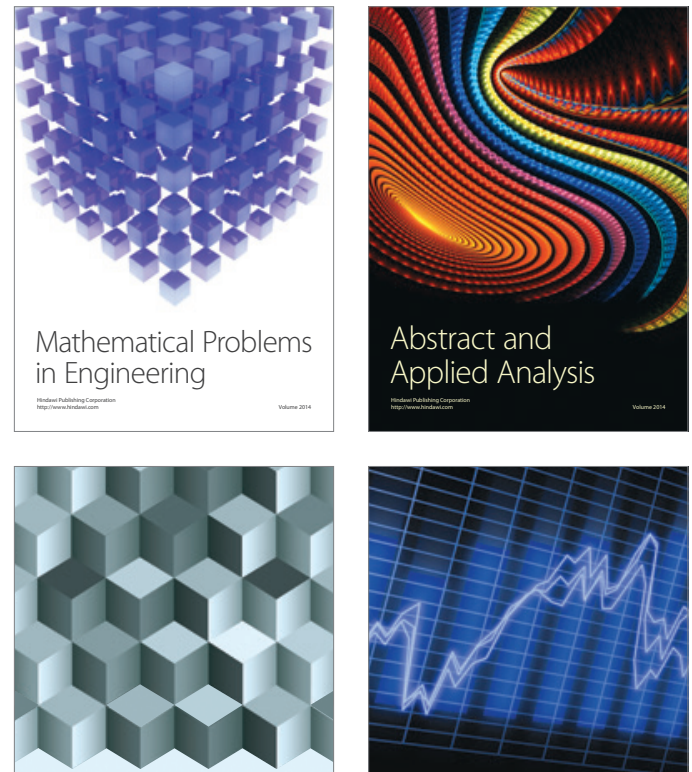

Journal of

Function Spaces

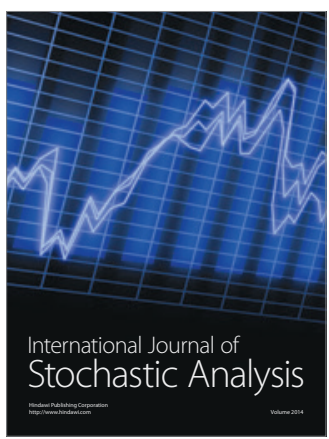

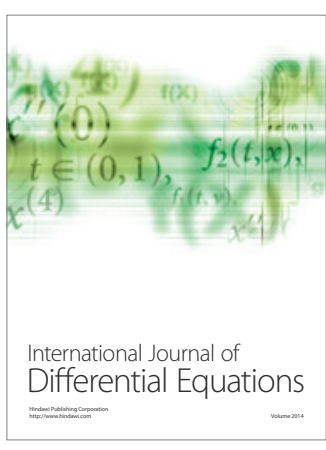
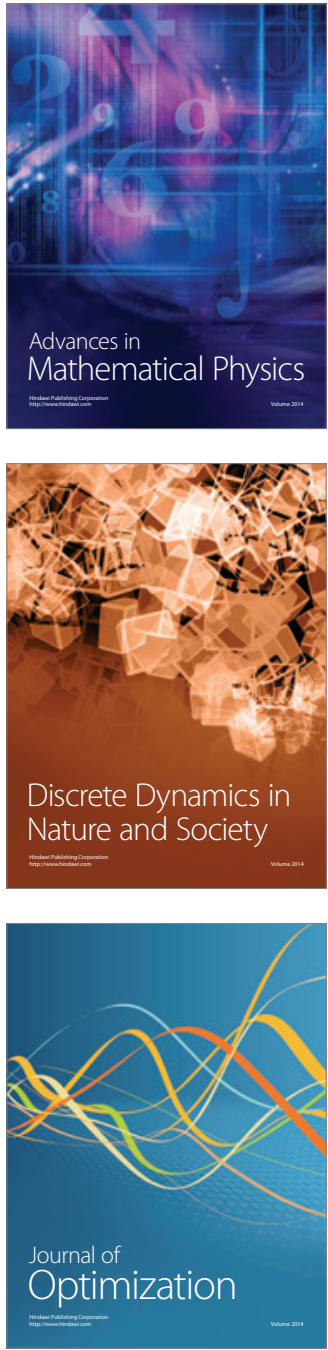